\title{
Mutation Abnormality
}

National Cancer Institute

\section{Source}

National Cancer Institute. Mutation Abnormality. NCI Thesaurus. Code C45576.

Any transmissible change in the genetic material of an organism, which can result from radiation, viral infection, transposition, treatment with mutagenic chemicals and errors during DNA replication or meiosis. The effects of mutation range from single base changes to loss or gain of complete chromosomes. As many of the simpler alterations to DNA may be repaired, such changes are only heritable once the change is fixed in the DNA by the process of replication. Mutations may be associated with genetic diversity or with pathologies including cancer. 